\title{
Is There an App for That?
}

\author{
Douglas Sellinger
}

$\mathrm{W}$ hen our only child arrived almost 16 years ago after a high-risk pregnancy, the first 2 things we purchased were a minivan and a cell phone with an external antenna. Shortly afterward, we merged onto the electronic highway with a home dial-up connection to the Internet.

Today, high-speed wireless Internet connects our menagerie of laptop and desktop computers, iPods, and smartphones to the rest of world. My daughter is lost without the ability to text, update her Facebook page, and instant-message with her friends and schoolmates, while listening to music and playing games. During my daughter's lifetime, technology has become ubiquitous in our home. And as if I don't get enough technology at home, I have also spent much of the past 15 years on teams that have added technology to the pharmacy department and health system where I work.

Patient safety and the safe use of medications have been significant forces leading the march of technology in hospital pharmacies. Bar-coding for bedside administration of medications, computerized physician order entry, electronic health records, automated dispensing machines, and decision-support software are increasingly tying pharmacists and pharmacies to a variety of workstations, tablets, netbooks and smartphones. You can get an "app" for your preferred drug information database, which allows you to use your smartphone for consultations, even if you can't access a workstation or laptop.

But these advances in technology are not failsafe, nor have they rendered pharmacists "redundant". For example, Saverno and colleagues (J Am Med Inform Assoc 2011;18[1]:32-37) reported what every pharmacist experiencing "alert fatigue" already knew: today's clinical decision-support software alerts users about too many irrelevant drug-drug interactions, yet sometimes missing interactions they do need to know about. Clinical decision-support software is improving, but some major strides are needed before it will provide pharmacists and prescribers with "smart" drug alerts that can be applied to specific clients.

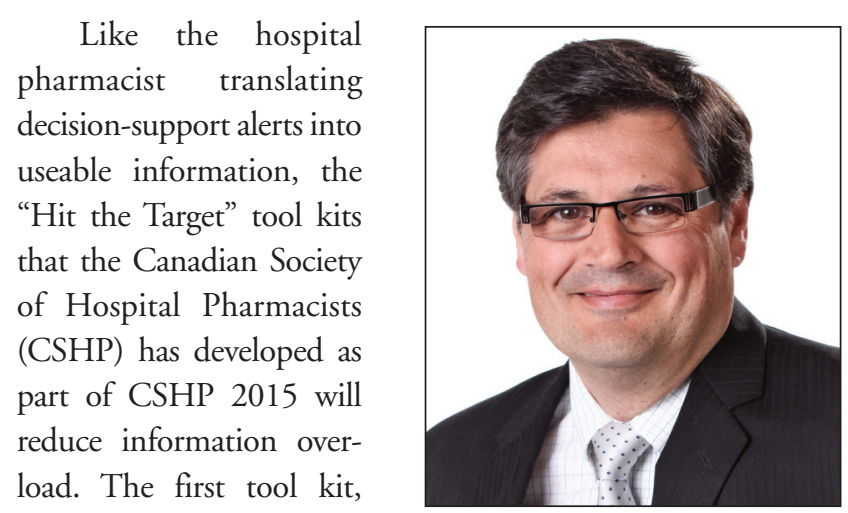

"From Paper to Practice:

Incorporating Evidence into Your Pharmacy Practice”, is now available online, with 2 more tool kits ("Complex Inpatients Need Medication Experts" and "One Dose at a Time") to follow soon. These tool kits provide a template for implementation, evaluation measures, and references to aid in implementing the changes required to meet their respective CSHP 2015 objectives.

In addition to the availability of the CSHP 2015 tool kits, I was excited to see the recent online addition of the extranet portal MY.CSHP.ca! I look forward to watching the growth of the CSHP online presence as the Society meets the communication and information needs of members. In this technologyrich era, enhancing the ways in which members can connect to CSHP enhances the Society's usefulness, improves the benefits of membership, and allows that unique sharing of ideas for improvement that I think sets Canadian pharmacists apart. Can the "CSHP app" for your iPhone, Android phone, or BlackBerry be far away?

Douglas Sellinger, BSP, MALT, will take on the role of President Elect and External Liaison for the Canadian Society of Hospital Pharmacists (CSHP) following the CSHP Annual General Meeting in August 2011. 